\title{
The False and the Furious
}

\section{Countering Misinformation and Negative Messaging in Breastfeeding Support}

Share this:

\author{
Kimberly Seals Allers, BA, MS
}

Social media has become an important source of information for new mothers. Many seek out information on breastfeeding. This is particularly true for low-income mothers who may not have paid access to credible news sources or to evidence-based journals. This may also perpetuate racial disparities in breastfeeding. Negative social media campaigns have highlighted the "dangers" of breastfeeding and used extremist language to brand breastfeeding supporters. This article suggests some specific strategies for addressing gaps in our current system and countering the negative information. Breastfeeding should be framed as a reproductive right.

Keywords: breastfeeding; social media; racial disparities

For years, mothers have had limited touchpoints for accessing breastfeeding information and support. But the prevalence of the internet and the rise of social media platforms have drastically changed the landscape for where and how mothers receive news in general and breastfeeding information and support, in particular. News consumption patterns have shifted, and communication has become increasingly personalized and polarized. In late 2016, Oxford Dictionaries selected "post-truth" as the word of the year, defining it as "relating to or denoting circumstances in which objective facts are less influential in shaping public opinion than appeals to emotion and personal belief."

Instead of traditional trusted outlets known for unbiased news or evidence-based research, a large body of research proves that people tend to focus on and self-select specific narratives to find an echo chamber. A 2016 study that analyzed 376 million Facebook users' interactions with over 900 news outlets found that people tend to seek information that aligns with their views (Schmidt et al., 2017).

In these changing times of multimedia, the user-generated content, the breakdown of trusted information sources, a political climate that attacks journalism, and segregated online environments, it can be harder to find credible breastfeeding support and information. With such a shifting digital-information environment, it is impossible to properly support mothers without acknowledging the social landscape, media climate, and the role of other influences that impact infant feeding decision-making. That landscape includes misinformation, disinformation, and a flurry of bad actors using

\footnotetext{
a.ksealsallers@gmail.com
}

advanced online tools to engage mothers and build audiences. ${ }^{1}$

\section{Disinformation and Racial Disparities in Breastfeeding}

The growing threat of misinformation and disinformation also has stark implications for perpetuating racial disparities in breastfeeding. Misinformation is a form of oppression, and whenever misinformation is prevalent, it is marginalized communities that often suffer the most. As media companies clamor to make money in the new digital age, online access to credible news sources now comes at a cost. For example, The New York Times only allows readers to access 10 articles a month (or on average, two articles a week) for free. After that, an online subscription costs about $\$ 15$ a month or $\$ 180$ a year. Access to evidence-based research via medical journals comes with an even heftier price tag out of reach for many low-income families. Therefore, the impact of who can afford access to credible information, and who is left to swim in the free misinformation superhighway and rely on social media, cannot be underestimated.

Also, many of these antibreastfeeding misinformation campaigns center the voices of middle- and upper-class White women and directly ignore or misrepresent the interests of communities of color. Often, one White woman's story becomes the rallying point for anger and antibreastfeeding sentiment, while ignoring the wide range of experiences of all women, especially women of color. The story of one somehow becomes a representation of the story of all. This perpetuates racist systems of power and privilege about whose stories are heard and whose are ignored. It undermines recent impactful work 
to reduce racial disparities and to change the "face" of breastfeeding.

\section{“The Dangers of Breastfeeding"}

The combination of these factors has created an unprecedented environment for communicating about breastfeeding, and the growing pervasiveness of misinformation and disinformation must be viewed as a dangerous and growing threat to the recent gains in breastfeeding initiation and duration. That threat includes the meteoric rise of organizations that leverage the echo-chamber trend to create emotionally charged and fear-based messaging, specifically spreading false information about the so-called "dangers" of exclusive breastfeeding. They attack breastfeeding-supportive organizations and agencies, including the Baby-Friendly Hospital Initiative. While highlighting the very important need to raise awareness about lactation failure and underfed babies, they dangerously paint with a broad brush over all exclusive breastfeeding.

The World Health Organization reports that over 800,000 babies could be saved worldwide by increasing breastfeeding rates, preventing $13 \%$ of all deaths under age 5. The Baby-Friendly Hospital Initiative recently reached the milestone of delivering its millionth birth, providing evidence-based care with positive outcomes. Yet, these organizations that spread misinformation have gained popularity, mainstream media coverage, and large followings on social media channels, sensationalizing relatively rare occurrences of infant death.

\section{Systemic Failures and Policy Gaps}

These movements have been aided and abetted by systemic failures and policy gaps that leave mothers without support, such as a lack of a federal paid maternity-leave policy. Hospitals are often understaffed with IBCLCs. Physicians receive very little training in lactation management and especially in diagnosing and treating lactation failure. There is no national standard for postpartum home visits. While most other cultures and countries have family and federal recognition of the postpartum period as one of rest and recuperation, most women in the United States return home to a vacuous hole of no support-many waiting until their 6-week checkup before seeing a healthcare professional. In addition to adapting to the maternal role changes, mothers experience emotional changes and fatigue during the postpartum period. At 2 months postpartum, researchers found that the prevalence of maternal fatigue was 55\% in Canada (Ansara, Cohen, Gallop, Kung, \& Schei, 2005), and $76 \%$ in the United States (Declercq,
Sakala, Corry, Applebaum, \& Risher, 2002). Stress can inhibit the letdown reflux causing problems with milk production.

Women also struggle in the postpartum period to establish their maternal identity, which is connected to having competence in mothering behaviors, such as breastfeeding. Yet, due to many structural barriers and social stressors, women don't feel competence in breastfeeding. For many, it takes time, a luxury not afforded to mothers in a country where, as a recent Department of Labor survey analysis revealed that one in four new mothers return to work in 10 days.

\section{No Acknowledgment for Women Who Couldn't Breastfeed}

Meanwhile, breastfeeding advocates have failed to publicly and collectively acknowledge the pain and trauma of failed breastfeeding experiences or have too narrowly defined "breastfeeding success" leaving many mothers without a community. Mothers who, often through no fault of their own, have stunted breastfeeding experiences, have gone looking for a "tribe" of similar experiences to seek comfort and release negative feelings of frustration and grief. The place they have found is one of the dangerous emotional manipulation and sophisticated communication tactics.

Certainly, many public health campaigns have also appealed to emotion and used persuasion to achieve behavioral change. However, the key differences between persuasion and manipulation bear noting. Persuasion is to induce a person through appeals to reason to freely accept-as his or her own-the beliefs, values, intentions, or actions advocated by the influence agent. Persuasion succeeds by improving, and not by undermining, a person's understanding of his or her situation (Faden, 1987). On the other hand, manipulation is defined as intentionally providing or taking advantage of fear, anxiety, pain, or other negative affective or cognitive states known to compromise a person's ability to process information effectively. Increasingly, we see fear mongering, scare tactics, and exploiting the emotional nature of the breastfeeding relationship as a tool for manipulating false narratives around exclusive breastfeeding and the Baby-Friendly Hospital movement.

\section{"The Extremist Effect": Breastfeeding Supporters Under Messaging Attack}

Researchers wanted to understand how to diminish people who support universally held values, such as wanting a clean environment, without being seen as 
directly attacking the value itself. The study, published by the International Society of Political Philosophy, showed a common political practice to "villify opponents as extremists in order to discredit their appeal to common values." Even if the group represents a consensus value such as equal opportunity, the extremist label suggests the group's agenda embodies an excessive and uncompromising representation of that value.

Through a series of experiments, the researchers discovered that by simply labeling those on the other side as "feminists" or "environmentalists" created a significant backlash against them. It was a proven political strategy to take something virtuous and turn it into vice by using language that calls it "extreme" or "radical." The study concluded that this "extremist effect" results in negative associations for the audience and is most effective in an environment where the public is unsure about what its priorities should be. In this regard, the continued labeling of breastfeeding supporters as "lactivists," "breastfeeding Nazis," and other variations of extremism is an intentional tactic being used to undermine breastfeeding sentiment and support.

The impact of that successful smear campaign is clear. Women are primed with a false narrative about lactation consultants as extreme and overbearing, so they see it-often even if it doesn't exist. Any support is perceived as pressure because that is what you were told to expect. In that regard, any action by well-meaning lactation consultants is judged against this narrative-even though most are no more zealous than a doctor encouraging you to stop smoking, or the constant public health reminders about seat belts.

\section{Industry Tactics Deja Vu}

Meanwhile, the tactics being used by these organizations to spread misinformation, and discredit breastfeeding and breastfeeding-supportive organizations, are eerily similar to those that have been used by industry giants in tobacco and Big Pharma for years. The Union of Concerned Scientists Center website features The Disinformation Playbook, created by the Center for Science and Democracy, giving concrete examples of industry strategies to misinform and buy influence. The playbook consists of five key tactics, such as "The Diversion," which is to manufacture uncertainty about science where little or none exists. "Corporations have deployed trade associations and front groups with innocuous-sounding names to undermine science, influence public opinion, and gain access to policymakers with maintaining the illusion of independence."
In "The Blitz," the play is to harass scientists who speak out with results of views inconvenient for industry. One example they provide is how the National Football League tried to intimidate scientists studying the evidence of a link between football and traumatic brain injuries. In breastfeeding, nearly every day on social media, the organization's leaders and associates attack and undermine breastfeeding advocates with social media comments, memes, and graphics. Their comments are often snarky, not focused on evidence but using name-calling and derision as the prime mode of attack.

Another industry strategy revealed in the playbook is called "The Fake," where organizations cherry-pick data and plant ghost-written articles in the media or scientific journals. For example, the Fed is Best Foundation (FIB), an organization that primarily uses social media for their campaign efforts, frequently uses this study as a prominent part of their positioning that exclusive breastfeeding is starving and often killing babies.

FIB statement: $10 \%$ of vaginally delivered and $25 \%$ of cesarean-delivered exclusively breastfed (EBF) babies lose excessive weight in the first days of life (Flaherman et al., 2015).

Fact: The reference actually reads almost 5\% (not 10\%) of vaginally delivered EBF infants lost at least $10 \%$ of their birth weight by 48 hours and $<25 \%$ (not $25 \%$ ) of cesarean-delivered EBF babies were at least $10 \%$ below birth weight by 72 hours. These statements are based on an analysis of California Kaiser Permanente retrospective data on 108,907 infants. From this information, Flaherman et al. (2015) developed a nomogram for EBF, term infant weight loss in the first 96 hours of life to help clinicians and lactation support providers "calibrate decision making to reflect [infant's] hour of age."

Another common misrepresentation of data is as follows.

FIB statement: A glucose of less than $46 \mathrm{mg} / \mathrm{dl}$ within the first 24 hours of life has been associated with a 3.7-fold increased risk of brain injury on MRI and a 4.8-fold increased odds of lower motor, cognitive, and language scores at 1 year of age (Tam et al., 2012).

Fact: The Tam et al. study was on infants at high risk for neonatal encephalopathy, not normal healthy term infants. Tam et al. subjects were $<36$ weeks with umbilical artery $\mathrm{pH}$ of $<7.1$, base excess $>10$ or a 5 -minute Apgar $\leq 5$. The authors sought to identify how many of these had hypoglycemia (16\%: they all received intravenous fluids with glucose), and if the presence of hypoglycemia 


\section{Parents, Put That Stranger's Breast Milk Down And Pick Up A Bottle Of Formula}

\section{우웅 (1)}

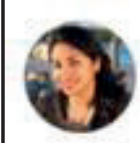

Kavin Senapathy. FULL BIO $\checkmark$

Ochions expenuad by Forbet Cor

\section{TWEET THIS}

Please don't hit up an unregt breast milk.
Don't Want To Breastfeed? The Case For Formula Feeding As An Informed Choice

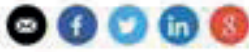

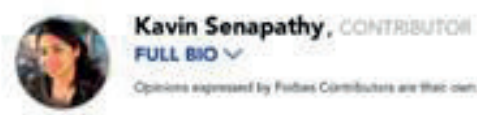

TWEeT THIS

in momensen anse hewer at thethen

Beware Of Accidentally Starving Your Breastfed Newborn, Warns The Fed Is Best Foundation

๑๑०७०

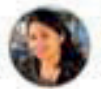

Kavin Senapathy.

nuke sio $\checkmark$

Continued from page 1

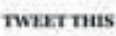

We know that not gettigg esough milk cas cause train damage in

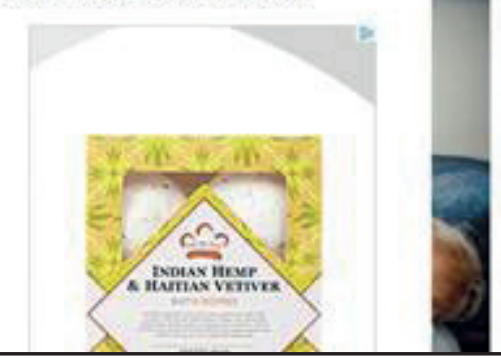

was associated with neurological problems at 1 year. It was, but these were not normal breastfed babies.

In addition, articles that are extremely critical of breastfeeding have appeared in reputable online magazines, such as Forbes, written by writers with known links to Monsanto and Big Business. This, again, is where the changing media landscape impacts the quality of information received. The need for content, and desire for "clicks" that generate advertising dollars, has made some online magazines loosen standards about who is considered a "journalist." The once-clear lines between commentary and objective news reporting are now blurred (Figures 1 and 2).

The Way Forward and Clinical Implications

We must also acknowledge missteps in messaging that have excluded many experiences and contributed to the fertile ground for emotional jockeying. Previous messaging frames in breastfeeding have ignored the realities of breastfeeding and left many mothers feeling unwelcome. The strategic focus on evidence-based practice, and on highlighting scientific benefits while women actually struggle with unsupportive maternity-leave policies, social norms, and the economic challenges of families, made the breastfeeding movement appear grossly disconnected from the reality of modern-day women's lives.

The long-standing "Breast is Best" message hinges on the benefits of breast milk instead of how women's lives, and maternal and infant health outcomes, are being materially changed by not having the basic infrastructure to successfully breastfeed for any meaningful duration. While "Breast is Best" is factually accurate, it only speaks to the act of breastfeeding and the benefits of human milk. It completely ignores the experience women often 


\section{WHY FORBES DELETED SOME KAVIN SENAPATHY ARTICLES}

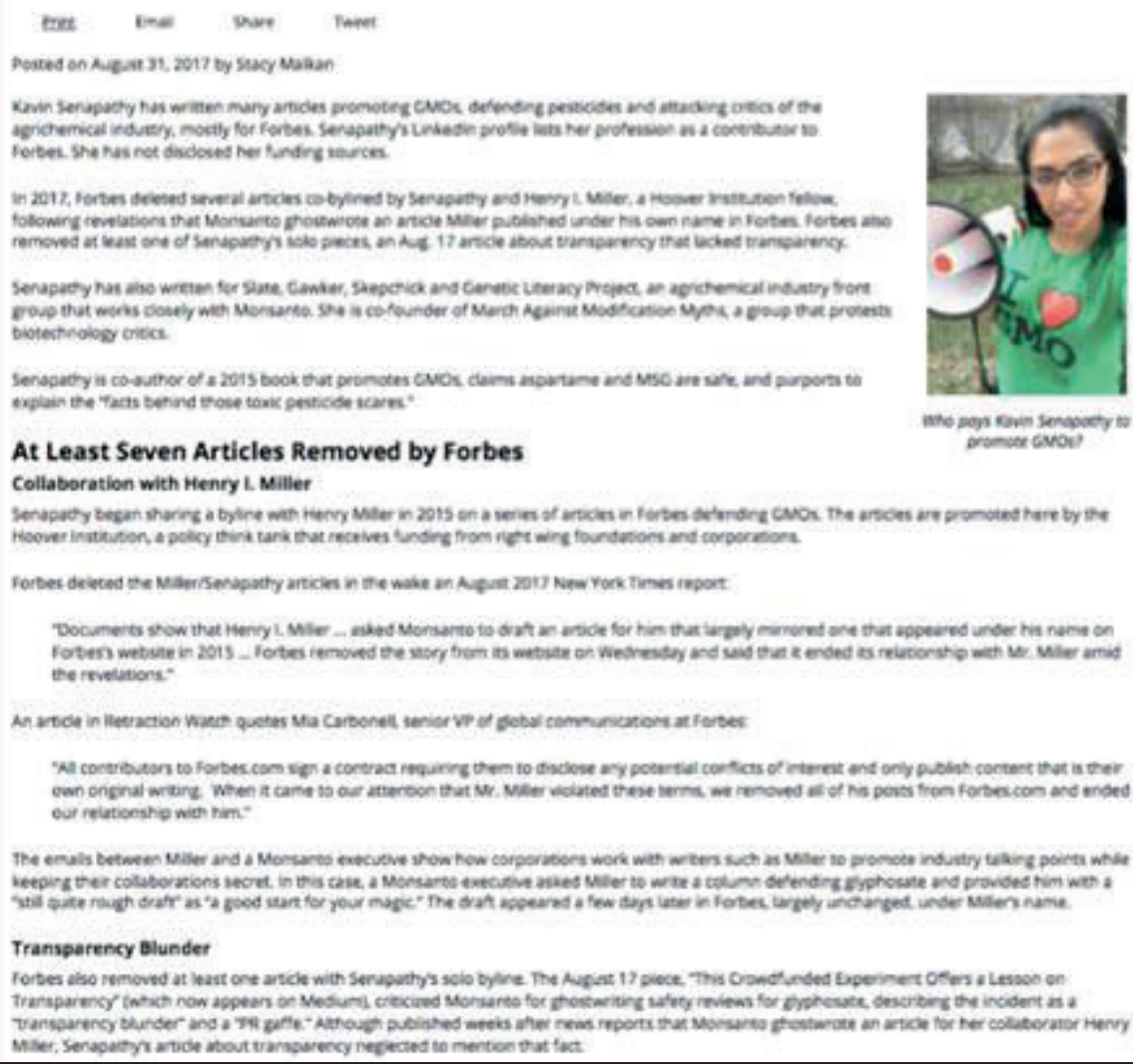

have when breastfeeding, as if our breasts are disconnected items from our bodies, and our bodies aren't impacted by the environment in which we exist.

Yes, breast milk is best for a baby, but breastfeeding amid policy failures, societal pressures, and systemic letdowns is the absolute worst. This focus on benefits, with little regard for the emotional toll it takes to deliver such benefits, has created a dangerous void. This void has been deftly leveraged by those who benefit from breastfeeding failure.

\section{Anger About Unsuccessful Breastfeeding}

Most immediately, we must acknowledge that yes, breastfeeding is amazing and wonderful, but for many, it can also have moments of frustration and anger. When women want to breastfeed and don't succeed, they are often disappointed and even traumatized. If you are saddened for that many years, that is trauma. That disappointment often leads to anger because society tells us that it doesn't matter if you don't breastfeed, and your baby will be "just fine," but the U.S. initiation rate of $80 \%$ tells us that many women actually want to. Not being able to breastfeed matters. In my travels, I meet mothers in their 50s and 60s, some with grandchildren, who tearfully tell me about how they were not able to successfully breastfeed or when they see the support their daughter is receiving and recognize all that they did not receive.

There is anger around breastfeeding-and for many, rightfully. But because women are angry about their breastfeeding experience does not mean breastfeeding should become "angrified." If we create the space and outlet for that anger to be discussed, then it can be properly handled. But advocates do not want to have that conversation because perhaps they too take it as a personal or collective failure, but this is an important shift for advocates and supporters alike. The system has failed us all-even well-meaning advocates and partners who face Herculean odds battling commercial interests and policy gaps to help women breastfeed successfully. 


\section{It's More Than Information}

We must stop assuming that if we simply keep arming women with more facts about breast milk, they will engage. As I wrote,

The movement sought to encourage women to choose to breastfeed by arming them with facts. Those facts included information about what is wrong with formula, but not what's wrong with society. We have courted women as the sole decision-makers on infant feeding, without considering how women were being influenced by societal barriers, partners, relatives, and marketing influences. (Seals Allers, 2017)

Women need a message and a moment that engages women as actors, with a role and a mission, not just as an audience.

\section{Give up "Time"}

We must reframe how we talk about breastfeeding and move away from time. Meaning that, in breastfeeding circles, we celebrate time spent exclusive breastfeeding. We celebrate 6-month exclusivity or 12 months of breastfeeding-which rightly acknowledges an important commitment, but leaves no space for those who have not put in that time, often through no fault of their own. If we know the multitude of barriers that women have scaled to successfully breastfeed for any meaningful duration, why not acknowledge that sometimes women don't breastfeed despite their best intent and effort, and we can understand that, too.

\section{Give Up Narrowly Defining Breastfeeding}

The need to narrowly define breastfeeding, or exclusive breastfeeding, is exclusionary and defeatist. It was used to create a unique club of select women for whom the perfect circumstances, ideal support, and good biology came together. Increasingly, this is becoming a smaller and smaller group. If we are only willing to "see" breastfeeding in this box, we will continue to miss many women-who often have second or third children and may want to try again-and continue to be labeled as small minded and unwelcoming. The "breastfeeding" spectrum must also include breast milk in a bottle, mixed feeding, or exclusively pumping as women deserving of support and celebration.

\section{Breastfeeding as a Reproductive Right}

"The surest way to inoculate a social movement is to keep it embroiled in the matter of choice," one movementbuilding expert told me. "It's precisely how to keep a social movement stuck in the cultural space because it masks what is really going on" (Seals Allers, 2017, pp. 220-221). When breastfeeding is framed as a choice, then we fail to differentiate how race, class, and other factors actually shape those choices.

As women fought to have control over when they have children, there was never any conversation about the right to feed the children that we did have. Breastfeeding is-and must be-framed as a reproductive right. Instead of trying to mobilize women around the scientific facts of breastfeeding, we will only be able to counter misinformation when we rally them around breastfeeding as a basic reproductive right and connect it to the status of their lives, in general. We must move reproductive rights away from just helping those who want to avoid or terminate a pregnancy, and extend our advocacy and protections to the families and children they are raising after pregnancy, and that means talking about breastfeeding. These conversations must be linked.

\section{Conclusions}

Advocates can successfully counter misinformation and disinformation in the long term by countering the narrative with a new way of messaging breastfeeding. The new "story of breastfeeding" must be more inclusive of varied experiences from exclusive breastfeeding to use of donor milk to mixed feeding. It must acknowledge the full scope of emotions-good and bad-that accompany breastfeeding in the United States and make space for those voices to be heard and validated.

\section{Note}

1. There is a key distinction between misinformation and disinformation. Misinformation is information that is false, but the person who is disseminating it believes that it is true. Disinformation is information that is false, and the person who is disseminating it knows it is false. It is a deliberate, intentional lie. For the purposes of this article, I will defer to using the word misinformation only because I do not make assumptions about any person's or organization's intent in scientific journals.

\section{References}

Ansara, D., Cohen, M. M., Gallop, R., Kung, R., \& Schei, B. (2005). Predictors of women's physical health problems after childbirth. Journal of Psychosomatic Obstetrics $\mathcal{E}$ Gynecology, 26(2), 115-125. http://dx.doi.org/10.1080/01443610400023064

Declercq, E. R., Sakala, C., Corry, M. P., Applebaum, S., \& Risher, P. (2002). Listening to mothers: Report of the first national U.S. survey of women's childbearing experiences. New York: Maternity Center Association. 
Faden, R. R. (1987). Ethical issues in government sponsored public health campaigns. Health Education Quarterly, 14(1), 27-37. http://dx.doi.org/10.1177/109019818701400105

Flaherman, V. J., Schaefer, E. W., Kuzniewicz, M. W., Li, S. X., Walsh, E. M., \& Paul, I. M. (2015). Early weight loss nomograms for exclusively breastfed newborns. Pediatrics, 135(1), e16-e23. http://dx.doi.org/10.1542/peds.2014-1532

Schmidt, A., Zollo, F., Del Vicario, M., Bessi, A., Scala, A., Caldarellia, C., \& Quattrociocchi, W. (2017). Anatomy of news consumption on Facebook.. http://www.pnas.org/content/ pnas/114/12/3035.full.pdf.

Seals Allers, K. (2017). The big letdown: How medicine, big business, and feminism undermine breastfeeding. New York, NY: St. Martin's Press.

Tam, E. W., Haeusslein, L. A., Bonifacio, S. L., Glass, H. C., Rogers, E. E., Jeremy, R. J., . . Ferriero, D. M. (2012).

Hypoglycemia is associated with increased risk for brain injury and adverse neurodevelopmental outcome in neonates at risk for encephalopathy. The Journal of Pediatrics, 161(1), 88-93. http://dx.doi.org/10.1016/j.jpeds.2011.12.047

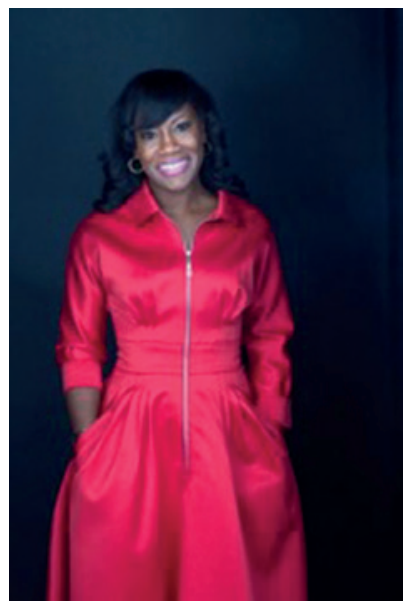

Kimberly Seals Allers, BA, MS, is an award-winning journalist, author, and an internationally recognized speaker, consultant, and advocate for maternal and infant health. A former senior editor at Essence and writer at Fortune magazine, Kimberly is a leading voice on the sociocultural and racial complexities of birth, breastfeeding, and motherhood. She was recently named one of the "21 Leaders for the 21st Century" by Women's eNews. A frequent contributor to The New York Times and Washington Post, last year, her online commentaries received over 8 million page views. Kimberly's fifth book, The Big Let Down-How Medicine, Big Business and Feminism Undermine Breastfeeding was published by St. Martin's Press in January 2017.

\section{Breastfeeding Program Evaluation Issue Brief, Summarized From NACCHO}

The National Association of County and City Health Officials has released an issue brief titled "Breastfeeding in the Community: Setting Up Your Own Monitoring and Evaluation Plan." The brief describes steps to develop monitoring and evaluation plans for community-level breastfeeding programs and shares lessons learned from the NACCHO Breastfeeding Project evaluation: https://www.naccho.org/uploads/ full-width-images/Breastfeeding-Setting-up-your-own-ME-plan.pdf

Source:USBC 